\title{
EVALUATION OF PHYSIOLOGICAL INDICES OF WATERLOGGING TOLERANCE OF DIFFERENT MAIZE VARIETIES IN SOUTH CHINA
}

\author{
LI, W. ${ }^{1 \#}-$ MO, W. ${ }^{1,2 \#}-$ ASHrAF, U. ${ }^{3 \#}-$ LI, G. ${ }^{1}-$ WEN, T. $^{1}-$ ABRAR, M. ${ }^{4}-$ GAO, L. ${ }^{1}-$ LIU, J. ${ }^{1 *}$ \\ $\mathrm{HU}, \mathrm{J} .^{1^{*}}$ \\ ${ }^{1}$ Crops Research Institute, Guangdong Academy of Agricultural Sciences, Guangdong \\ Provincial Key Laboratory of Crop Genetic Improvement, Guangzhou, China
} ${ }^{2}$ Department of Crop science and Technology, College of Agriculture, South China Agricultural
University, Guangzhou, 510640, Guangdong, China

\author{
${ }^{3}$ Department of Agronomy, University of Agriculture, Faisalabad, Pakistan \\ ${ }^{4}$ State Key Laboratory of Grassland Agro-Ecosystems, School of Life Sciences, Lanzhou \\ University, Lanzhou, China \\ *Corresponding authors \\ e-mails:liu_jhxs@163.com(J.Liu); Jghu2003@263.net (J.Hu) \\ ${ }^{\#}$ Equal contributors \\ (Received $11^{\text {th }}$ Jan 2018; accepted $13^{\text {th }}$ Mar 2018)
}

\begin{abstract}
Maize is extremely sensitive to waterlogging stress. A pot experiment was conducted to study the morpho-physiological characteristics of 18 differrent maize cultivars (widely grown in South China) under waterlogging stress at seedling stage. Results showed that maize shoot growth was inhibited in terms of plant height and dry weight whilst leaf chlorophyll contents were also decreased under waterlogging stress. Root length, root hairs, root surface area and root volume were also declined under waterlogged conditions. Furthermore, activity of antioxidants i.e., superoxide dismutase (SOD), peroxidase (POD), and catalase (CAT) were increased considerably under waterlogging stress compared to control. The soluble protein content also increased in some maize cultivars whereas malondialdehyde (MDA) contents were found to be decreased in some cultivars that may be due to higher antioxidant enzyme activities. Furthermore, the principal component analysis (PCA) showed that the coefficients of comprehensive indices $(\mathrm{Z})$ for protein contents, SOD, POD and CAT were higher in $\mathrm{Z1}$, the soluble protein content and MDA content in $\mathrm{Z} 2$ while the SPAD and $\mathrm{F}_{\mathrm{v}} / \mathrm{F}_{\mathrm{m}}$ values in $\mathrm{Z} 3$ were remained higher than other parameters.
\end{abstract}

Keywords: antioxidant enzymes, chlorophyll, maize, root, waterlogging stress

\section{Introduction}

Maize is an important food crop in the world (Ashraf et al., 2016), whereas China is ranked first with respect to area under maize cultivation and yield (Qi et al., 2012). Maize is more susceptible to water logging stress, especially at seedling stage thus resulting in poor stand establishment (Ren et al., 2016a). Anaerobic conditions due to waterlogging, inhibit the growth of plant roots, causing decline in root/shoot ratio and root dry weight thus indirectly affect the aboveground growth (Grzesiak et al., 2014; McDaniel et al., 2016; Yu et al., 2017). In response to waterlogging stress, maize root cells cleave to form aeration tissue for maintaining oxygen diffusion and high absorption efficiency (Zaidi et al., 2003). Most of the previous studies which are related to aboveground response of maize to waterlogging showed that plant height, dry weight 
and leaf photosynthesis severely got affected by waterlogging (Ren et al., 2016b; Shin et al., 2016; Wang et al., 2012). Lipid peroxidation caused chloroplastic membrane destruction is one of the responses of plants to waterlogged conditions. It results in chlorophyll destruction causing reduction in the efficiency of PSII $\left(\mathrm{F}_{\mathrm{v}} / \mathrm{F}_{\mathrm{m}}\right)$ (Mielke and Schaffer, 2010; Yordanova and Popova, 2007).

Plants produce reactive oxygen species (ROS), such as hydrogen peroxide $\left(\mathrm{H}_{2} \mathrm{O}_{2}\right)$, superoxide anions $\left(\mathrm{O}^{2-}\right)$, hydroxyl radical $\left({ }^{\circ} \mathrm{OH}\right)$ and singlet oxygen $\left({ }^{1} \mathrm{O}_{2}\right)$ in the absence of oxygen (Cheng et al., 2015; Pucciariello and Perata, 2016). Excessive ROS induce damage to proteins, lipids, carbohydrates and DNA, thus causing cell lipid peroxidation, which is harmful to plant (Gill and Tuteja, 2010). Malondialdehyde (MDA) is the final product of lipid peroxidation so its content can reflect the degree of membrane lipid peroxidation. Plants have developed an antioxidant system including superoxide dismutase (SOD), peroxidase (POD), catalase (CAT) and other antioxidant enzymes to control ROS levels and regulate various physiological processes which play an important role in plant adaptation and tolerance to abiotic stress (Hossain et al., 2009; Wang et al., 2016a). Previous studies showed that the trend of antioxidant enzymes activity increase transiently and then decrease sharply with the increase of waterlogging (Gill and Tuteja, 2010; Liu et al., 2015a). Furthermore, plants regulate the cell osmotic potential and protect the function of various enzymes through the biosynthesis and accumulation of osmotic adjustment (Wu et al., 2015; Yordanova and Popova, 2007).

Membership function is often used for comprehensive evaluation of crop waterlogging stress (Zhou et al., 2003). However, there is a certain limitation on the comprehensive evaluation of crop waterlogging tolerance by the membership function because of the correlation between indicators. The principal component analysis can convert the original indexes into new comprehensive and independent indicators (Liu et al., 2015b). The comprehensive evaluation value of each variety can be obtained by weighing the value of each comprehensive index and the corresponding membership function value of varieties. This study was aimed to explore the morphological and physiological responses of 18 different Chinese maize varieties to waterlogging stress.

\section{Materials and methods}

\section{Experimental material and growing conditions}

A pot experiment was conducted by using 18 maize varieties, i.e., Guangtian 2 (GT2), Xinmeixiazhen (XMXZ), Huameitian 8 (HMT8), Guangnuo 1 (GN1), Xinmeixiangnuo (XMXN), Zhengtian 68 (ZT68), Yuexiannuo 2 (YXN2), Yuetian 13 (YT13), Yuebainuo 3 (YBN33), Yuetian 27 (YT27), Yuetian 28 (YT28), Yuebainuo 6 (YBN6), Zhengtian 89 (ZT89), Yuecainuo 2 (YCN2), Yuehuanuo 1 (YHN1), Yuezinuo 5 (YZN5), Yuetian 16 (YT16), Yuetian 22 (YT22) provided by Crop Research Institute, Guangdong Academy of Agricultural Sciences, Guangzhou, China. 30 seeds were evenly planted in each plastic pot $(10 \mathrm{~cm}$ in height and $6 \mathrm{~cm}$ in diameter) containing $500 \mathrm{~g}$ soil with $22.87 \mathrm{~g} \cdot \mathrm{kg}^{-1}$ organic matter, available nitrogen $10.03 \mathrm{mg} \cdot \mathrm{kg}^{-1}$, available phosphorus $70.21 \mathrm{mg} \cdot \mathrm{kg}^{-1}$, available potassium $100.41 \mathrm{mg} \cdot \mathrm{kg}^{-1}$ and $\mathrm{pH} 6.8$. The pots were placed at Agricultural Meteorological Observatory in South China Agricultural University and covered with a transparent plastic shed from the top. 


\section{Treatments}

Each variety included control (no waterlogging) and waterlogging treatments having three replications. All pots were filled with water to $3 \mathrm{~cm}$ above the soil surface at three leaves stage except control and waterlogged conditions were maintained for two days. The samples were taken and the related morphological indexes were determined within $12 \mathrm{~h}$ after draining the water.

\section{Observations}

\section{Morphological characters}

The plant height was measured from soil surface to the highest tip of leaves. The fresh sample of plant shoots was placed in the oven at $75^{\circ} \mathrm{C}$ and dried to a constant weight for measurement of the shoot dry weight. The shoot dry weight of the plant was weighed by the electronic analytical balance (BSA224S, Sartorius, Taiwan).

\section{Root morphological index determination}

The root was scanned with Epson Expression 10000XL (Epson America Inc., Long Beach, US). After scanning, the root morphological indexes i.e., root length, root mean diameter, root surface area and root volume were analyzed by WinRHIZO image analysis system (Regent Instruments Inc., CA).

\section{SPAD value and chlorophyll fluorescence determination}

The relative chlorophyll content of leaves was measured by a SPAD meter (SPAD502, Konica-Minolta, Japan), a precise and rapid method of leaf chlorophyll determination. 10 leaves were determined for each treatment and the SPAD values were measured at the upper, middle and lower parts in each leaf. The chlorophyll fluorescence was measured with a modulated chlorophyll fluorometer (FMS-2, Hansatech Instruments, Norfolk, UK) according to Wang et al. (2012): Minimal fluorescence $\left(\mathrm{F}_{0}\right)$ was measured after leaves adapted to dark for $30 \mathrm{~min}$, and maximal fluorescence $\left(\mathrm{F}_{\mathrm{m}}\right)$ was induced by strong saturation pulsed light after leaves adapted to dark for 30 min. The maximum efficiency of PSII $\left(\mathrm{F}_{\mathrm{v}} / \mathrm{F}_{\mathrm{m}}\right)$ was calculated as $\left(\mathrm{F}_{\mathrm{m}}-\mathrm{F}_{0}\right) / \mathrm{F}_{\mathrm{m}}$.

\section{Physiological parameters}

To determine physiological parameters, the second and third leaves of plant sample were collected and stored in refrigerator at $-80{ }^{\circ} \mathrm{C}$ till biochemical analyses.

Enzyme was extracted by adding $0.30 \mathrm{~g}$ fresh sample to $4 \mathrm{~mL}$ of $0.05 \mathrm{~mol} \cdot \mathrm{L}^{-1}$ phosphate buffer $(\mathrm{pH}=7.8)$ in an ice bath, and then solution was transferred into $5 \mathrm{~mL}$ centrifuge tube for centrifugation at $8000 \mathrm{rpm}$ at $4{ }^{\circ} \mathrm{C}$ for $15 \mathrm{~min}$. The supernatant is the enzyme solution.

The superoxide dismutase (SOD, EC 1.15.1.1) activity was measured by using nitro blue tetrazolium (NBT) method $(\mathrm{Li}, 2000)$. The reaction mixture contained $1.5 \mathrm{~mL}$ of $0.5 \mathrm{mmol} \cdot \mathrm{L}^{-1}$ phosphate buffer $(\mathrm{pH}=7.8), 0.3 \mathrm{~mL}$ of $130 \mathrm{mmol} \cdot \mathrm{L}^{-1}$ methionine, $0.3 \mathrm{~mL}$ of $0.75 \mathrm{mmol} \cdot \mathrm{L}^{-1}$ of nitro-tetrazolium chloride Blue, $0.3 \mathrm{~mL}$ of $0.02 \mathrm{mmol} \cdot \mathrm{L}^{-1}$ riboflavin, $0.3 \mathrm{~mL}$ of $0.1 \mathrm{mmol} \cdot \mathrm{L}^{-1}$ EDTA-Na, $0.05 \mathrm{~mL}$ enzyme solution and $0.25 \mathrm{~mL}$ distilled water. Phosphoric buffer $(\mathrm{pH}=7.8)$ was used as control. After mixing, the light was irradiated under $4000 \mathrm{~lx}$ for $20 \mathrm{~min}$, and the reaction was stopped by covering with black cloth. Then, the color changed was measured at $560 \mathrm{~nm}$ and one unit of SOD 
activity equaled the volume of extract needed to cause $50 \%$ inhibition of the color reaction and expressed as $\mathrm{U} \cdot \mathrm{g}^{-1}$.

The peroxidase (POD, EC1.11.1.7) activity was measured by using guaiacol method ( $\mathrm{Li}, 2000$ ). One cuvette was added with $1 \mathrm{~mL}$ of $0.3 \% \mathrm{H}_{2} \mathrm{O}_{2}, 0.95 \mathrm{~mL}$ of $0.2 \%$ guaiacol, $1 \mathrm{~mL}$ of phosphate buffer $(\mathrm{pH}=7.0)$ and $0.05 \mathrm{~mL}$ of $0.05 \mathrm{~mol} \cdot \mathrm{L}^{-1}$ phosphate buffer $(\mathrm{pH}=7.8)$ as a zero tube. The other one was added with $1 \mathrm{~mL}$ of $0.3 \% \mathrm{H}_{2} \mathrm{O}_{2}, 0.95 \mathrm{~mL}$ of $0.2 \%$ guaiacol, $1 \mathrm{~mL}$ phosphate buffer $(\mathrm{pH}=7.0)$ and $0.05 \mathrm{~mL}$ enzyme solution. The color changed was measured at $470 \mathrm{~nm}$ immediately, and an absorbance value was recorded after every $30 \mathrm{~s}$ for $2 \mathrm{~min}$. One POD unit of enzyme activity was defined as the absorbance increase because of guaiacol oxidation by $0.01\left(\mathrm{U} \cdot \mathrm{g}^{-1}\right)$.

The catalase (CAT, EC 1.11.1.6) activity was measured by ultraviolet spectrophotometry (Wang et al., 2016b). One quartz cuvette $(3 \mathrm{~mL})$ was added with $1.95 \mathrm{~mL}$ of distilled water, $1.00 \mathrm{~mL}$ of $0.3 \% \mathrm{H}_{2} \mathrm{O}_{2}$ solution and $0.05 \mathrm{~mL}$ of PBS buffer $(\mathrm{pH}=7.8)$. The other one was added with sodium phosphate buffer instead of the enzyme solution. The other one was added with the enzyme solution instead of PBS buffer. After rapid mixing, the color change was measured at $240 \mathrm{~nm}$, and an absorbance value was recorded after every $30 \mathrm{~s}$ for $2 \mathrm{~min}$. The absorbance changed by 0.01 per minute is a relative activity of the CAT unit $\left(\mathrm{U} \cdot \mathrm{g}^{-1}\right)$.

The malondialdehyde (MDA) content was determined by thiobarbituric acid method ( $\mathrm{Li}, 2000)$. One test tube was added with $1.5 \mathrm{~mL}$ supernatant, $2 \mathrm{~mL}$ of $0.5 \%$ thiobarbituric acid (TBA) solution and phosphate solution. The other one was added with $1.5 \mathrm{~mL}$ of $0.05 \mathrm{~mol} \cdot \mathrm{L}^{-1}$ phosphate buffer $(\mathrm{pH}=7.8)$ and $2 \mathrm{~mL}$ of $0.5 \%$ thiobarbituric acid solution as control. Test tubes were heated at $100{ }^{\circ} \mathrm{C}$ for $30 \mathrm{~min}$ and then cooled in an ice bath immediately. After centrifugation at $3000 \mathrm{rpm}$ for $15 \mathrm{~min}$, the supernatant was taken and the absorbance was measured at 450, 532and $600 \mathrm{~nm}$. The MDA content $\left(\mu \mathrm{mol} \cdot \mathrm{L}^{-1}\right)$ was calculated as: MDA content $=6.45\left(\mathrm{OD}_{532}-\mathrm{OD}_{600}\right)$ $0.56 \mathrm{OD}_{450}$.

Soluble protein content was determined by Coomassie brilliant blue G-250 method (Bradford, 1976). The supernatant was mixed with the Coomassie brilliant blueG-250 solution and the absorbance of the reaction mixture was read at $595 \mathrm{~nm}$ with a spectrophotometer. Solution protein content was determined from a standard curve (bovine serum albumin) and expressed as $\mu \mathrm{g} \cdot \mathrm{g}^{-1}$.

\section{Statistical analysis}

Analyses of variances (ANOVA) were performed by the Linear Model Procedure of Statistix version 8 (Statistix 8, Analystical, Tallahassee, Florida, USA). Comparisons of means among different treatments were made according to the least significant difference (LSD) at the 5\% probability level. The figures were made by using the Graph Pad Prism 6 for Windows (Graph Pad Software Inc., CA, USA).

\section{Comprehensive evaluation}

The evaluation system of different maize varieties to waterlogging was established by waterlogging tolerance coefficient, principal component analysis, membership function and cluster analysis based on the response mechanism of maize to waterlogging.

Waterlogging tolerance coefficient (WTC) was used to measure waterlogging tolerance of varieties. WTC could eliminate difference between varieties and treatments. 
The WTC was calculated as: WTC $=$ Mean value of treatment/Mean value of control (Liu et al., 2010b).

Principal component analysis (PCA) was used to analyze the WTC of investigated parameters, and the original investigated parameters were converted into new independent comprehensive indexes.

Membership function (MF) was further used to assess the comprehensive indexes. The membership function value of the comprehensive index is obtained by the following formula (Eq. 1) according to (Zhou et al., 2003):

$$
U\left(X_{j}\right)=\left(X_{j}-X_{\min }\right) /\left(X_{\max }-X_{\min }\right)
$$

where $X_{j}$ is the $j$ th comprehensive index, $X_{\min }$ is the minimum of $j_{t h}$ comprehensive index, and $X_{\max }$ is the maximum of $j_{\text {th }}$ comprehensive index.

The weight of each comprehensive index is calculated by the contribution rate (Eq. 2):

$$
\mathrm{W}_{j}=\frac{p_{j}}{\sum_{j=1}^{n} P_{j}}
$$

where $\mathrm{W}_{\mathrm{j}}$ is the weight of $\mathrm{jth}$ comprehensive index in all comprehensive indicators, and $\mathrm{P}_{\mathrm{j}}$ is the contribution rate of the $\mathrm{jth}$ comprehensive index.

The following formula (Eq. 3) was used to estimate the waterlogging tolerance of different maize varieties:

$$
\mathrm{D}=\sum_{j=1}^{n}\left[U\left(X_{j}\right) \times W_{j}\right]
$$

\section{Results}

\section{Analysis of variance of the investigated parameters}

All maize varieties differed significantly regarding most of the investigated parameters except for $\mathrm{F}_{\mathrm{v}} / \mathrm{F}_{\mathrm{m}}$ value in leaves. Waterlogging also affected most of the investigated parameters; however, no significant effect was noted for SPAD value in leaves and root volume. For variety and waterlogging interaction, the significant effects were observed for most of the investigated parameters, except for $F_{v} / F_{m}$ value in leaves (Table 1).

\section{Morphological characters}

Waterlogging significantly reduced the plant height of XMXZ, GN1, YT13, TBN3, YT27, YT28, YHN1, YZN5 and YT22 by $18.62 \%-43.33 \%$, compared with the control (Fig. 1A). After waterlogging, the shoot dry weight was significantly reduced by $60.00 \%, 39.13 \%, 33.33 \%$ and $57.14 \%$ for HMT8, YBN3, TBN 6, YHN1 respectively, while other varieties did not have significant difference (Fig. 1B).

\section{Root morphological characters}

Waterlogging treated seedlings significantly decreased root length of XMXN, YBN3, YCN2, YHN1, YZN5, YT16 and YT22 by 23.52\%-61.56\%, compared to the control 
(Fig. 2A). As for root surface area, there is a significant decrease in XMXN, YBN3, YCN2, YHN1and YZN5, while a notable increase in shoot was observed for GT2 (Fig. 2B). In addition, a significant improvement in root mean diameter was recorded for XMXZ, HMT8, XMXN, ZT68, YBN3, YT27, YHN1 and YT16 (Fig. 2C). After waterlogging, the root volume was significantly improved for GT2, XMXZ, HMT8, ZT68and YT27in different degrees, whereas an obvious decline is observed in YT 13, ZT89, YCN 2, YHN1and YZN5 (Fig. 2 D).

Furthermore, the results of variance analysis showed that there was no significant change in the root volume of maize seedling after waterlogging, this change was due to the difference of genotype (Table 1).

Table 1. Analysis of variance of the investigated parameters ( $F$ value)

\begin{tabular}{c|c|c|c}
\hline Index & $\mathbf{V}$ & $\mathbf{T}$ & $\mathbf{V} \times \mathbf{T}$ \\
\hline Plant Height & $14.21^{* *}$ & $98.02^{* *}$ & $3.02^{* *}$ \\
Shoot dry weight & $11.1^{* *}$ & $33.82^{* *}$ & $5.07^{* *}$ \\
SPAD value in leaves & $7.03^{* *}$ & $3.00 \mathrm{~ns}$ & $2.11^{*}$ \\
$\mathrm{~F}_{\mathrm{v}} / \mathrm{F}_{\mathrm{m}}$ value & $1.67 \mathrm{~ns}$ & $16.57^{* *}$ & $1.91 \mathrm{~ns}$ \\
CAT activity in leaves & $106.42^{* *}$ & $275.81^{* *}$ & $7.41^{* *}$ \\
POD activity in leaves & $110.69^{* *}$ & $273.39^{* *}$ & $7.35^{* *}$ \\
SOD activity in leaves & $110.29^{* *}$ & $273.94^{* *}$ & $7.37^{* *}$ \\
MDA content in leaves & $79.64^{* *}$ & $20.37^{* *}$ & $30.15^{* *}$ \\
Soluble protein & $43.52^{* *}$ & $254.69^{* *}$ & $23.72^{* *}$ \\
Root length & $23.13^{* *}$ & $188.25^{* *}$ & $9.11^{* *}$ \\
Root surface area & $19.56^{* *}$ & $34.17^{* *}$ & $8.78^{* *}$ \\
Root mean diameter & $6.97^{* *}$ & $123.24^{* *}$ & $7.29^{* *}$ \\
Root volume & $39.11^{* *}$ & $2.94 \mathrm{~ns}$ & $20.95^{* *}$ \\
\hline
\end{tabular}

$\mathrm{V}$, variety; $\mathrm{T}$, treatment; $\mathrm{V} \times \mathrm{T}$, variety and treatment interaction; $\mathrm{ns}$, non-significant at $\mathrm{P}<0.05$ level; *, significant at $\mathrm{P}<0.05$ level; $* *$, significant at $\mathrm{P}<0.01$ levels
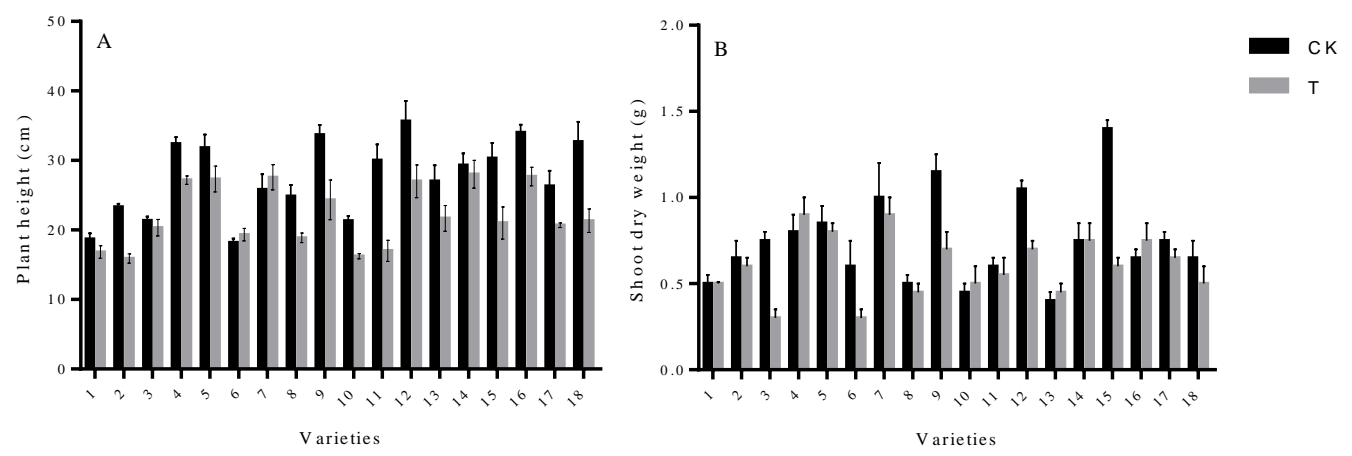

Figure 1. Plant height and shoot dry weight of maize (A and B, respectively). Capped bars represent standard error. Variety 1-18 represents GT2, XMXZ, HMT8, GN1, XMXN, ZT68, YXN2, YT13, YBN33, YT27, YT28, YBN6, ZT89, YCN2, YHN1, YZN5YT16 and YT22, respectively 

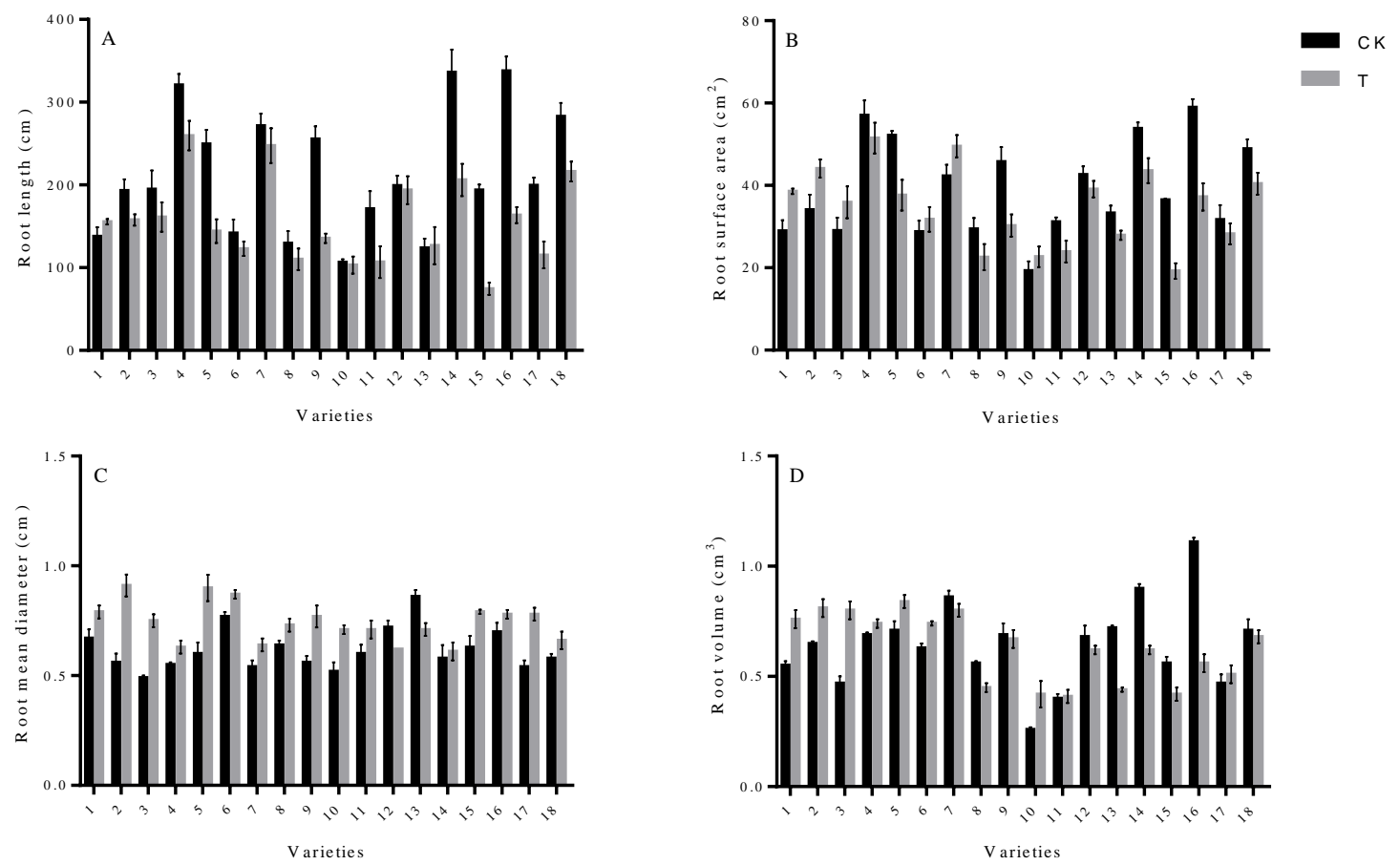

Figure 2. Root length, root surface area, root mean diameter and root volume of maize $(A, B$, $C, D$, respectively). Capped bars represent standard error. Variety 1-18 representsGT2, XMXZ, HMT8, GN1, XMXN, ZT68, YXN2, YT13, YBN33, YT27, YT28, YBN6, ZT89, YCN2, YHN1, YZN5YT16 and YT22, respectively

\section{SPAD value and chlorophyll fluorescence}

There was no significant effect of waterlogging on chlorophyll content in maize, and the difference of SPAD value was due to the difference among varieties. The SPAD value was significantly reduced in YT28, YBN6 and YHN1. Nevertheless, nonsignificant effect of waterlogging treatment was observed for SPAD value in other varieties (Fig. 3A). For $\mathrm{F}_{\mathrm{v}} / \mathrm{F}_{\mathrm{m}}$ value, significant decline was recorded for YBN3, ZT89 and YT22 up to $7.35 \%, 11.09 \%$ and $14.36 \%$, respectively. Additionally, no significant changes were observed in remaining varieties (Fig. 3B).
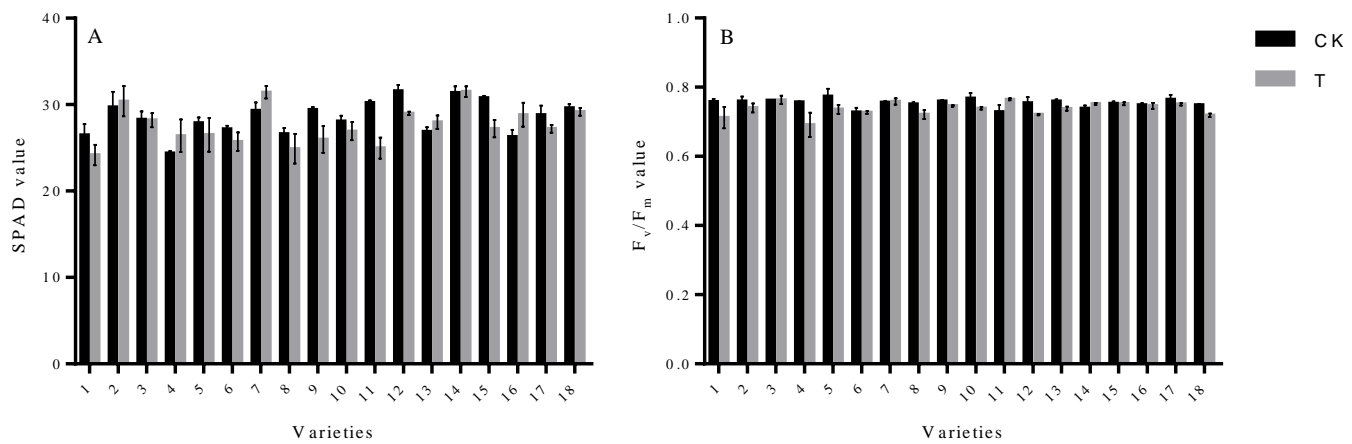

Figure 3. SPAD value and $F_{1} / F_{m}$ value in leaves of maize (A and B). Capped bars represent standard error. Variety 1-18 representsGT2, XMXZ, HMT8, GN1, XMXN, ZT68, YXN2, YT13, YBN33, YT27, YT28, YBN6, ZT89, YCN2, YHN1, YZN5YT16 and YT22, respectively 


\section{Antioxidant enzymatic activities}

Waterlogging treated maize seedlings significantly increased SOD activity of XMXZ, HMT8, GN 1, XMXN, YT 13, YBN3, YT28, TBN 6, ZT 89, YCN 2, YZN5 and YT22. This increase in SOD activity ranged from $19.16 \%$ to $56.89 \%$ (Fig. 4A). The POD activity was also induced by waterlogging treatment, and significant increase in XMXZ, HMT8, GN1, XMXN, ZT68, YT13, YBN3, YT28, TBN 6, ZT 89, YCN2, YZN5 and YT22 was observed ranging from $19.16 \%$ to $106.96 \%$ (Fig. 4B). Significant increment of CAT activity was recorded for HMT8, GN1, XMXN, YT13, YT28, TBN 6, YCN2, YZN5and YT22 ranging from $26.08 \%$ to $57.29 \%$ (Fig. 4C).
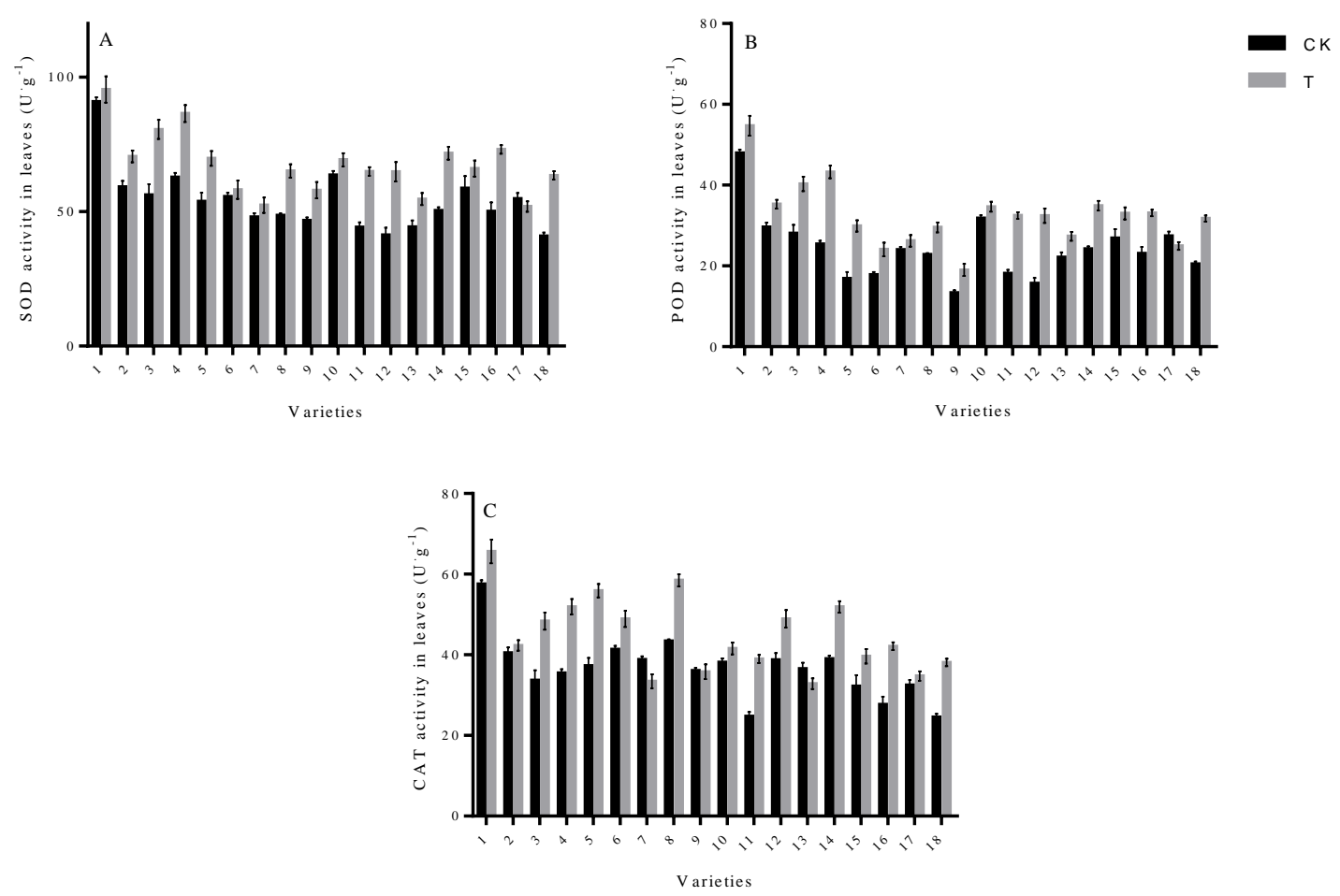

Figure 4. $S O D, P O D, C A T$ activity in leaves of maize ( $A, B, C$ respectively). Capped bars represent standard error. Variety 1-18 representsGT2, XMXZ, HMT8, GN1, XMXN, ZT68, YXN2, YT13, YBN33, YT27, YT28, YBN6, ZT89, YCN2, YHN1, YZN5YT16 and YT22, respectively

\section{Protein content and MDA content}

For protein content, waterlogging treatment significantly improved protein content of GT2, XMXZ, HMT8, GN1, YXN2, YT13, YHN1, YZN5 and YT16 by $136.22 \%$, $15.45 \%, 72.34 \%, 27.49 \%, 21.02 \%, 16.59 \%, 37.32 \%, 37.39 \%$ and $21.23 \%$, respectively (Fig. 5B). Apart from GT2, HMT8, YT13 and TBN6, the MDA contents of remaining varieties were reduced. Especially, waterlogging reduced MDA contents of XMXZ, XMXN and YXN2 significantly by $24.49 \%, 33.68 \%$ and $24.67 \%$, respectively (Fig. 5A). 

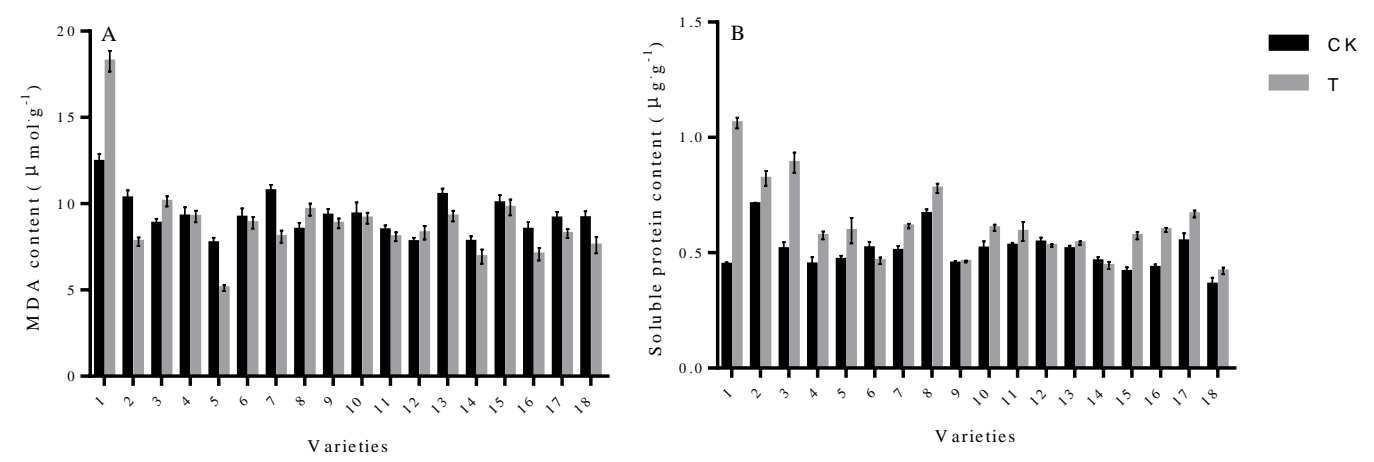

Figure 5. MDA content and soluble protein content in leaves of maize (A and B). Capped bars represent standard error. Variety 1-18 represents GT2, XMXZ, HMT8, GN1, XMXN, ZT68, YXN2, YT13, YBN33, YT27, YT28, YBN6, ZT89, YCN2, YHN1, YZN5YT16 and YT22, respectively

\section{Comprehensive evaluation}

The original investigated parameters were converted into three comprehensive indexes to analyze the WTC of physiological parameters using PCA (Table 2).

Table 2. Coefficients of comprehensive indexes (Z) and proportion

\begin{tabular}{c|c|c|c|c|c|c|c|c}
\hline & $\begin{array}{c}\text { SOD } \\
\text { activity }\end{array}$ & $\begin{array}{c}\text { POD } \\
\text { activity }\end{array}$ & $\begin{array}{c}\text { CAT } \\
\text { activity }\end{array}$ & $\begin{array}{c}\text { Soluble } \\
\text { protein }\end{array}$ & $\begin{array}{c}\mathbf{F}_{\mathbf{v}} / \mathbf{F}_{\mathbf{m}} \\
\text { value }\end{array}$ & $\begin{array}{c}\text { SPAD } \\
\text { value }\end{array}$ & $\begin{array}{c}\text { MDA } \\
\text { content }\end{array}$ & Proportion \\
\hline $\mathrm{Z} 1$ & 0.582 & 0.559 & 0.477 & -0.230 & 0.030 & 0.188 & -0.178 & 0.364 \\
$\mathrm{Z} 2$ & 0.124 & 0.135 & 0.292 & 0.609 & -0.308 & -0.134 & 0.630 & 0.251 \\
$\mathrm{Z} 3$ & 0.004 & 0.003 & 0.246 & -0.013 & 0.663 & -0.703 & 0.071 & 0.192 \\
\hline
\end{tabular}

From Table 2, it can be noted that the coefficient of protein content, SOD, POD and CAT activity in Z1 is larger, the soluble protein content and MDA content in Z2 is larger, while the SPAD and $\mathrm{F}_{\mathrm{v}} / \mathrm{F}_{\mathrm{m}}$ value in $\mathrm{Z3}$ is larger. The contribution rates of the three comprehensive indexes (Z1, Z2, Z3) were $36.46 \%, 25.12 \%$ and $19.20 \%$ respectively, and the cumulative contribution rate was $80.78 \%$. It can be used to evaluate the tolerance of maize.

The membership function analysis of all the comprehensive indexes of maize varieties showed that there was more resistance of the cultivar to waterlogging at larger $\mathrm{U}$ value on the same comprehensive index. Took $\mathrm{Z} 1$ as example, under waterlogging, the U(1) value of YBN6 was the largest, indicating that YBN6 had the best waterlogging resistance compared withGT2 having minimum U(1) value which indicated that GT2 had less resistance against waterlogging. D value is a comprehensive index reflecting the waterlogging resistance of maize varieties. The higher $\mathrm{D}$ value indicated better resistance against waterlogging. Using K-means clustering using D values, the varieties can be divided into three categories. The varieties can be divided into three categories using $\mathrm{D}$ values. The first category being the waterlogging tolerant variety, included YT28, TBN6, YT22 and HMT8. The second category being the moderately waterlogging tolerant varieties includes XMXN, YZN5, GN1, YCN2, YT13, YCN1, GT2, YBN3 and ZT68, while the third category indicated waterlogging sensitive variety i.e., YT27, XMXZ, ZT 89, YT16 and YXN2 (Table 3). 
Table 3. The value of each variety's comprehensive index (Z), index weight (IW), $U(x), D$

\begin{tabular}{c|c|c|c|c|c|c|c|c}
\hline \multirow{2}{*}{ Varieties } & \multicolumn{2}{|c|}{ Comprehensive index } & \multicolumn{2}{c|}{ Membership function value } & \multirow{2}{*}{ D } & Waterlogging \\
& tolerance \\
\hline GT2 & -2.87 & 3.89 & -0.12 & 0.00 & 1.00 & 0.37 & 0.40 & 11 \\
XMXZ & -0.74 & -1.25 & -0.83 & 0.39 & 0.11 & 0.23 & 0.27 & 15 \\
HMT8 & 0.49 & 1.62 & 0.51 & 0.62 & 0.61 & 0.49 & 0.59 & 4 \\
GN1 & 1.47 & 1.16 & -2.04 & 0.80 & 0.53 & 0.00 & 0.53 & 7 \\
XMXN & 1.5 & -0.15 & -0.15 & 0.81 & 0.30 & 0.36 & 0.55 & 5 \\
ZT68 & -0.74 & -1 & 0.65 & 0.39 & 0.15 & 0.52 & 0.35 & 13 \\
YXN2 & -1.5 & -1.89 & -0.88 & 0.25 & 0.00 & 0.22 & 0.17 & 18 \\
YT 13 & -0.05 & 0.89 & 0.26 & 0.52 & 0.48 & 0.44 & 0.49 & 9 \\
YBN33 & -0.68 & -0.61 & 0.66 & 0.41 & 0.22 & 0.52 & 0.38 & 12 \\
YT 27 & -1.51 & -0.34 & -0.36 & 0.25 & 0.27 & 0.32 & 0.27 & 14 \\
YT28 & 1.83 & 0.04 & 3.16 & 0.87 & 0.33 & 1.00 & 0.73 & 1 \\
YBN 6 & 2.53 & 0.5 & -1.48 & 1.00 & 0.41 & 0.11 & 0.61 & 2 \\
ZT 89 & -0.83 & -1.19 & -1.11 & 0.38 & 0.12 & 0.18 & 0.25 & 16 \\
YCN 2 & 1.05 & -0.95 & 0.74 & 0.73 & 0.16 & 0.53 & 0.51 & 8 \\
YHN1 & -1.15 & 0.05 & 1.31 & 0.32 & 0.34 & 0.64 & 0.40 & 10 \\
YZN 5 & 1.56 & -0.13 & -0.4 & 0.82 & 0.30 & 0.32 & 0.54 & 6 \\
YT16 & -2.31 & -0.86 & 0.17 & 0.10 & 0.18 & 0.43 & 0.20 & 17 \\
YT22 & 1.94 & 0.23 & -0.09 & 0.89 & 0.37 & 0.38 & 0.61 & 3 \\
IW & & & & 0.45 & 0.31 & 0.24 & & \\
\hline
\end{tabular}

\section{Discussion}

Root is an important plant part that absorbs water and nutrients from soil. The wellgrowing roots ensure higher photosynthetic efficiency, higher yield and stability (Hayashi et al., 2013). Previous studies showed that the morphological parameters of winter wheat roots were significantly reduced after waterlogging, especially the root number and root length, thus inhibited the absorption of water and nutrients (Dickin and Wright, 2008). Waterlogging led to root hypoxia, inhibiting mitochondrial respiration and ATP synthesis (Liu et al., 2014). Due to energy constraints, the ability of roots to absorb water and nutrients is reduced, that results in the reduction of root growth rate and dry matter accumulation (Wang et al., 2012). Root/shoot ratio reflects the correlation between plant shoots and roots, sothe reduction in root/shoot ratio indicates maize growth inhibition (Grzesiak et al., 2014). In this study, waterlogging inhibited maize root and lateral root growth. Overall, root length, root surface area and root volume of most maize varieties were lower than non-waterlogging conditions, however, the root morphological changes were as follows: the roots became shorter and thicker, the root hair and their bifurcation also suffered decline. The order of inhibition for root morphological indexes was: root length > root surface area > root volume > root mean diameter. These results corroborate with the findings of Liang et al. (2009). Waterlogging causes root hypoxia, thus indirectly affecting the growth and development of shoots (Qi et al., 2012). Waterlogging inhibited the growth of plant shoots which resulted in the reduction of plant height (Shin et al., 2016). Waterlogging at seedling stage inbibits seedling growth whereas reduction in plant height is directly related to flooding duration (Liu et al., 2013). The results of this study showed that the plant 
height of different maize seedlings decreased varying from different degree of waterlogging.

Previous studies showed that waterlogging caused decline in stomatal conductance and chlorophyll content of maize seedlings that resulted in reduced net photosynthetic rate and destruction of photosynthetic electron transport system (Ahmed et al., 2002; Wang et al., 2012). In this study, waterlogging caused a decline in SPAD value and $\mathrm{F}_{\mathrm{v}} / \mathrm{F}_{\mathrm{m}}$ value. Chlorophyll is an important photosynthetic pigment and its content affects the plant's ability to assimilate photosynthetic products. The reduction in chlorophyll content is a sensitive indicator for abiotic stress (Candan and Tarhan, 2012). Waterlogging led to the leaf senescence and chlorophyll degradation thus affecting the accumulation of photosynthetic products, leading to biomass reduction (Ren et al., 2016b; Wang et al., 2016a). A decline in $\mathrm{F}_{\mathrm{v}} / \mathrm{F}_{\mathrm{m}}$ values under water logged conditions, showed the destruction of PSII photochemical reaction (Baker, 2008; Liu et al., 2010a).

Soluble proteins participate in the osmotic regulation of plant cells. Accumulation of soluble proteins maintains plant cell osmotic potential, and increases plant tolerance to waterlogging stress (Yu et al., 2017). In this study, the soluble protein content in most of maize varieties was improved compared with the control, especially in the GT2, having significance increase of $136.22 \%$. While in a previous study, the content of soluble protein in DH605 and ZD958 leaves decreased by $12.5 \%$ and $8.4 \%$ respectively, after 6 days of flooding at three-leaf stage (Wu et al., 2014). Combined with these results, the soluble protein content showed inverse relation with the flooding duration.

Waterlogging induced regulations of antioxidant enzymes i.e.,SOD, POD and CAT and lipid peroxidation (in terms of MDA content) (Figures 4). Activity of antioxidant enzymes (SOD, POD and CAT) was found higher in most seedlings under waterlogged conditions, however waterlogging stress lowered MDA content in most of maize varieties (Fig. 5A). Antioxidant enzymes effectively scavenged the ROS generated by biological or non-biological stress in plant, thereby protecting the cell membrane and improving plant resistance (Gill and Tuteja, 2010; Wang et al., 2016a). Antioxidant enzymes removed excessive free radicals such as superoxide-radical $\left(\mathrm{O}^{2-}\right)$ and hydrogen peroxide $\left(\mathrm{H}_{2} \mathrm{O}_{2}\right)$ from cells thus maintaining ROS at a low level and allowing intracellular ROS production and scavenging to be in a dynamic equilibrium state (Hao et al., 2003; Liu et al., 2014). Waterlogging induced antioxidant enzyme activity in plants to reduce the damage caused by ROS. This activity of antioxidant enzyme was positively correlated with waterlogging resistance (Yin et al., 2010). MDA is the final product of lipid peroxidation. It acts in combination with the cell membrane to inhibit functional proteins from destructing cell structure and function thus ultimately affecting cell metabolism (Liu and Jiang, 2015). Previous studies showed that MDA content in wheat increased significantly after 7 days of flooding. It accelerated the degree of lipid peroxidation by causing severe damage to the cell membrane (Yu et al., 2017). In this study, the results differed from previous studies due to differences in flooding time and decline in MDA content may be due to the scavenging of antioxidant enzyme. In this case of prolonged flooding time, there may be a significant increase in MDA content because waterlogging may resulted in the destruction of the antioxidant enzymes (Liu et al., 2015a). ROS stimulated the protection mechanism of antioxidant enzymes to prevent maize from short-term flooding. But the activity of antioxidant enzymes declined sharply with the increase in flooding duration (Wu et al., 2014).

Evaluation of the waterlogging resistance of maize is a complex problem and it is difficult to evaluate comprehensively with single index. The basic aim of screening and 
breeding waterlogged resistant varieties of maize is to establish an evaluation system which contains varieties, treatments and indicators (Wang et al., 2007; Zhou et al., 2003). Principal component analysis can transform the individual indicators into comprehensive indicators and then calculate the weight according to the contribution rate of each comprehensive index (Liu et al., 2015b). Membership function is used to calculate the membership function value of each comprehensive index. Through the weight calculation, we can get the comprehensive evaluation value ( $D$ value) of maize waterlogging tolerance. In this study, the waterlogging tolerance of maize varieties was evaluated by principal component analysis, membership function and cluster analysis as: YT28>TBN6>YT22>HMT8>XMXN>YZN5>GN1>YCN2>YT13>YHN1>GT2>YBN 3>ZT68>YT27>XMXZ>ZT89>YT16>YXN2.

\section{Conclusion}

In this experiment, the morphological characteristics and physicochemical properties of different maize varieties under seedling waterlogging were studied. Overall, water logging conditions at early stages hampered the morphological and physiological traits of maize. The results may have some limitations requiring further conformational experiments. In addition, waterlogging evaluation system of different maize varieties was established according to their response mechanism. This evaluation system provided a theoretical basis for exploring the physiological basis of maize waterlogging.

Author contributions. W. L., T. W., J. L. and J. H. designed the research, W. L., W. M. and G. L. performed the experiments and collected the data, W. L., A. U., W. M., J. L. and J. H. analyzed the data and wrote the manuscript, W. L., A. U., and M. A. edited the manuscript and provided guidance during experimentation.

Acknowledgments. This research was supported by the Project of the Guangdong Province Science and Technology Program (2015B020202006, 2016B020233004, 2016A030303030, 2016A020210030, 2017B020203003, 2017A030303045, 2017B090907023), and the Team Project of Guangdong Agricultural Department (2017LM2148), and the President Fund project of the Guangdong Academy of Agricultural Sciences (201509,201510).

\section{REFERENCES}

[1] Ahmed, S., Nawata, E., Hosokawa, M., Domae, Y., Sakuratani, T. (2002): Alterations in photosynthesis and some antioxidant enzymatic activities of mungbean subjected to waterlogging. - Plant Sci. 163: 117-123.

[2] Ashraf, U., Salim, M. N., Sher, A., Sabir, S. U. R., Khan, A., Pan, S. G., Tang, X. (2016): Maize growth, yield formation and water-nitrogen usage in response to varied irrigation and nitrogen supply under semi-arid climate. - Turk. J. Field Crops 21: 88-96.

[3] Baker, N. R. (2008): Chlorophyll fluorescence: a probe of photosynthesis in vivo. Annu. Rev. Plant Biol. 59: 89-113.

[4] Bradford, M. M. (1976): A rapid and sensitive method for the quantitation of microgram quantities of protein utilizing the principle of protein-dye binding. - Anal. Biochem. 72: $248-254$.

[5] Candan, N., Tarhan, L. (2012): Tolerance or sensitivity responses of Mentha pulegium to osmotic and waterlogging stress in terms of antioxidant defense systems and membrane lipid peroxidation. - Environ. Exp. Bot. 75: 83-88. 
[6] Cheng, X.-X., Yu, M., Zhang, N., Zhou, Z.-Q., Xu, Q.-T., Mei, F.-Z., Qu, L.-H. (2015): Reactive oxygen species regulate programmed cell death progress of endosperm in winter wheat (Triticum aestivum L.) under waterlogging. - Protoplasma 253: 311-327.

[7] Dickin, E., Wright, D. (2008): The effects of winter waterlogging and summer drought on the growth and yield of winter wheat (Triticum aestivum L.). - Eur. J. Agron. 28: 234244.

[8] Gill, S. S., Tuteja, N. (2010): Reactive oxygen species and antioxidant machinery in abiotic stress tolerance in crop plants. - Plant Physiol. Biochem. PPB Soc. Francaise Physiol. Veg. 48: 909-930.

[9] Grzesiak, M. T., Szczyrek, P., Rut, G., Ostrowska, a., Hura, K., Rzepka, a., Hura, T., Grzesiak, S. (2014): Interspecific differences in tolerance to soil compaction, drought and waterlogging stresses among maize and triticale genotypes. - J. Agron. Crop Sci. 201: 330-343.

[10] Hao, Y. L., Pan, J. B., Zhang, Q. Z., Yang, J. (2003): Effect of waterlogging on growth and generation at different stages in maize. - Chin. Agric. Sci. Bull. 2003(6): 58-60+63.

[11] Hayashi, T., Yoshida, T., Fujii, K., Mitsuya, S., Tsuji, T., Okada, Y., Hayashi, E., Yamauchi, A. (2013): Maintained root length density contributes to the waterlogging tolerance in common wheat (Triticum aestivum L.). - Field Crops Res. 152: 27-35.

[12] Hossain, Z., López-Climent, M. F., Arbona, V., Pérez-Clemente, R. M., Gómez-Cadenas, A. (2009): Modulation of the antioxidant system in citrus under waterlogging and subsequent drainage. - J. Plant Physiol. 166: 1391-1404.

[13] Li, H. S. (2000): Principle and Technology of Plant Physiological and Biochemical Experiment. - Higher Education Press, Beijing.

[14] Liang, Z. J., Tao, H. B., Wang, P. (2009): Recovery effects of morphology and photosynthetic characteristics of maize seedlings after waterlogging. - Acta Ecol. Sin. 29: 3977-3986.

[15] Liu, M., Jiang, Y. (2015): Genotypic variation in growth and metabolic responses of perennial ryegrass exposed to short-term waterlogging and submergence stress. - Plant Physiol. Biochem. 95: 57-64.

[16] Liu, M., Li, Y., Guo, G. H., Liu, H. Y., Li, G. H., Wang, S. H., Liu, Z. H., Ding, Y. F. (2015a): Comparison on submergence tolerance of different type rice at tillering stage in lower reaches of Yangtze River. - Chin. J. Appl. Ecol. (26)5: 1373-1381.

[17] Liu, M. Y., Sun, J., Wang, K. Y., Liu, D., Li, Z. Y., Zhang, J. (2014): Spermidine enhances waterlogging tolerance via regulation of antioxidant defence, heat shock protein expression and plasma membrane $\mathrm{H}+$-ATPase activity in Zea mays. - J. Agron. Crop Sci. 200: 199-211.

[18] Liu, R. X., Jing, Y. X., Xiao, L., Li, G. L., Yang, D. J., Nie, K. Y. (2010a): Effects of flooding depth on gas exchange, chlorophyll fluorescence and growth of Melaleuca alternifolia seedlings. - Acta Ecol. Sin. 30(19): 5113-5120.

[19] Liu, Y. Z., Tang, B., Zhang, Y. L., Ma, K. J., Xu, S. Z., Qiu, F.Z. (2010b): Screening methods for waterlogging tolerance at maize (Zea mays L.) seedling stage. - Agr Sci China 3: 362-369.

[20] Liu, Z., Zhou, W., Lv, J., He, P., Liang, G., Jin, H. (2015b): A simple evaluation of soil quality of waterlogged purple paddy soils with different productivities. - PloS One 10: 116.

[21] Liu, Z. G., Liu, Z. D., Xiao, J. F., Nan, J. Q., Gong, W. J. (2013): Waterlogging at seedling and jointing stages inhibits growth and development, reduces yield in summer maize. - Trans. Chin. Soc. Agric. Eng. 29(5): 44-52.

[22] McDaniel, V., Skaggs, R. W., Negm, L. M. (2016): Injury and recovery of maize roots affected by flooding. - Appl. Eng. Agric. 32: 627-638.

[23] Mielke, M. S., Schaffer, B. (2010): Leaf gas exchange, chlorophyll fluorescence and pigment indexes of Eugenia uniflora L. in response to changes in light intensity and soil flooding. - Tree Physiol. 30: 45-55. 
[24] Pucciariello, C., Perata, P. (2016): New insights into reactive oxygen species and nitric oxide signalling under low oxygen in plants. - Plant Cell Environ. 40(4): 473-482.

[25] Qi, W.-Z., Liu, H.-H., Liu, P., Dong, S.-T., Zhao, B.-Q., So, H. B., Li, G., Liu, H.-D., Zhang, J.-W., Zhao, B. (2012): Morphological and physiological characteristics of corn (Zea mays L.) roots from cultivars with different yield potentials. - Eur. J. Agron. 38: 5463.

[26] Ren, B., Zhang, J., Dong, S., Liu, P., Zhao, B. (2016a): Root and shoot responses of summer maize to waterlogging at different stages. - Agron. J. 108: 1060-1069.

[27] Ren, B., Zhang, J., Dong, S., Liu, P., Zhao, B. (2016b): Effects of duration of waterlogging at different growth stages on grain growth of summer Maize (Zea mays L.) under field conditions. - J. Agron. Crop Sci. 202: 564-575.

[28] Shin, S., Kim, S.-G., Jung, G.-H., Kim, C.-G., Son, B.-Y., Kim, J. T., Kim, S. G., Yang, W., Kwon, Y., Shim, K.-B., et al. (2016): Evaluation of waterlogging tolerance with the degree of foliar senescence at early vegetative stage of maize (Zea mays L.). - J. Crop Sci. Biotechnol. 19: 393-399.

[29] Wang, F., Liu, J., Zhou, L., Pan, G., Li, Z., Zaidi, S. H.R., Cheng, F. (2016a): Senescence-specific change in ROS scavenging enzyme activities and regulation of various SOD isozymes to ROS levels in psf mutant rice leaves. - Plant Physiol. Biochem. 109: 248-261.

[30] Wang, J., Zhou, M. X., Xu, R. G., Lu, C., Huang, Z. L. (2007): Studies on selecting indices and evaluation methods for barley's (Hordeum vulgare L.) waterlogging tolerance. - Sci. Agric. Sin. 40: 2145-2152.

[31] Wang, Q., Liu, Z. W., Xu, W. J. (2016b): Ultraviolet spectrophotometry measurement of catalase activity in maize. - Chin. Agric. Sci. Bull. 32(15): 159-165.

[32] Wang, X., Liu, T., Li, C., Chen, H. (2012): Effects of soil flooding on photosynthesis and growth of Zea mays L. seedlings under different light intensities. - Afr. J. Biotechnol. 11: 7676-7683.

[33] Wu, B. C., Zhang, J. W., Li, X., Fan, X., Dong, S. T., Zhao, B., Liu, P. (2014): Effect of waterlogging on leaf senescence characteristics of summer maize in the field. - Chin. J. Appl. Ecol. 25(4): 1022-1028.

[34] Wu, S., Hu, C., Tan, Q., Li, L., Shi, K., Zheng, Y., Sun, X. (2015): Drought stress tolerance mediated by zinc-induced antioxidative defense and osmotic adjustment in cotton (Gossypium Hirsutum). - Acta Physiol. Plant. 37: 167.

[35] Yin, D., Chen, S., Chen, F., Guan, Z., Fang, W. (2010): Morpho-anatomical and physiological responses of two Dendranthema species to waterlogging. - Environ. Exp. Bot. 68: 122-130.

[36] Yordanova, R. Y., Popova, L. P. (2007): Flooding-induced changes in photosynthesis and oxidative status in maize plants. - Acta Physiol. Plant. 29: 535-541.

[37] Yu, M., Zhou, Z., Deng, X., Li, J., Mei, F., Qi, Y. (2017): Physiological mechanism of programmed cell death aggravation and acceleration in wheat endosperm cells caused by waterlogging. - Acta Physiol. Plant. 39: 23.

[38] Zaidi, P. H., Rafique, S., Singh, N. N. (2003): Response of maize (Zea mays L.) genotypes to excess soil moisture stress: Morpho-physiological effects and basis of tolerance. - Eur. J. Agron. 19: 383-399.

[39] Zhou, G. S., Mei, F. Z., Zhou, Z. Q., Zhu, X. B. (2003): Comprehensive evaluation and forecast on physiological indices of waterlogging resistance of different wheat varieties. Sci. Agric. Sin. 36(11): 1378-1382. 